\title{
Un día de Hambre
}

\author{
A Day of Hunger \\ Um Dia da Fome \\ Javier Fernández Álvarez \\ Diplomado Universitario en Enfermería. Hospital de Begoña. Cooperante con Fundación Pablo Horstmann \\ Cómo citar este artículo en edición digital: Fernández Álvarez, J. (2015). Un día de Hambre. Cultura de los Cuidados (Edición \\ digital), 19(43). Disponible en:< http://dx.doi.org/10.14198/cuid.2015.43.06> \\ Correspondencia: C/Acacia $n^{\circ} 52^{\circ}$ Dch. Gijón. \\ Correo electrónico: jfernandez_alvarez@hotmail.com \\ Recibido: 09/06/2015; Aceptado: 12/09/2015
}

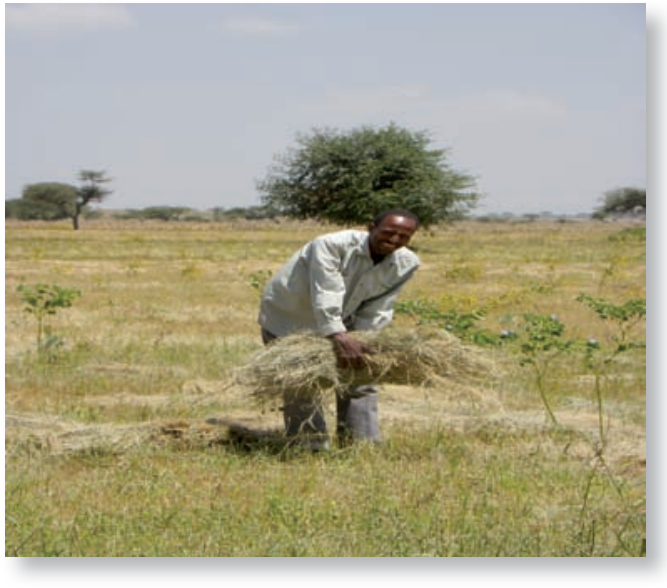

Imagen 1 Padre en su huerta

\section{ABSTRACT}

My experience as a volunteer in Africa made me reflect on the importance of the death of a child and look for different situations and cultures. In European society, we assume that parents should outlive their children and who would die for their children. In Ethiopia where families can not afford to make a minimum contribution of food needed, mothers come in such bad shape that they are unable to give breastfeeding, and people are accustomed to the early years are the most critical, the most difficult, as they are accustomed to losing in those years to his brothers, sons, grandsons, nephews and friends.

Keywords: Transcultural nursing; experiences; cooperation.

\section{RESUMO}

Minha experiência como voluntário na África me fez refletir sobre a importância da morte de uma criança e olhar para diferentes situações e culturas. $\mathrm{Na}$ sociedade europeia, assumimos que os pais devem sobreviver a seus filhos e que morreria por seus filhos. $\mathrm{Na}$ Etiópia, onde as famílias não têm condições de fazer uma contribuição mínima de alimentos necessária, as mães vêm em tão má forma que eles são incapazes de dar a amamentação, e as pessoas estão acostumadas aos primeiros anos são os mais críticos, o mais difícil, já que eles estão acostumados a perder naqueles anos a seus irmãos, filhos, netos, sobrinhos e amigos.

Palavras-chave: Enfermagem transcultural; experiências; cooperação.

\section{RESUMEN}

Mi vivencia en África como cooperante me hizo reflexionar sobre la importancia de la muerte de un hijo y la mirada desde diferentes situaciones y culturas. En la sociedad europea, suponemos que los progenitores deben sobrevivir a sus hijos y que darían la vida por sus hijos. En Etiopía donde familias no tienen dinero suficiente para asegurarse un aporte mínimo de los alimentos necesarios, las madres vienen en tan malas condiciones que son incapaces de dar la lactancia, y las personas están acostumbradas a que los primeros años 
son los más críticos, los más difíciles, en que están acostumbrados a perder en esos años a sus hermanos, hijos, nietos, sobrinos o amigos.

Palabras clave: Enfermería transcultural; experiencias; cooperación.

Eran las seis de la mañana en Meki (Etiopía), un pueblo en medio de una carretera, un pueblo de paso, donde los camioneros paran como mucho a degustar los platos típicos en cualquiera de los bares dispuestos en la carretera principal, un pueblo escondido bajo el polvo en el viento, un pueblo de chabolas de barro en el Centro de África. Estaba sentado con la espalda apoyada contra la pared de la casa de voluntarios, los pájaros alzaban el vuelo desde los árboles. En más de una ocasión había visto como algún pobre despistado, que se apresuraba en su despertar, se daba de bruces contra el edificio. El cielo del amanecer anaranjado con tonos rojizos, suplantaba poco a poco el azul oscuro brillante, salpicado de estrellas fugaces, a las que les pedía siempre el deseo de no tener que irme de Meki.

Las siete de la mañana, me acerqué a la entrada, como era previsible las mamás hacían cola, esperaban a que se abriese la puerta $y$ pasar, para tener número. Muchas habían caminado varias horas para llegar, para llegar primero, para no quedarse sin sitio y poder volver en el mismo día a su hogar lo antes posible, donde posiblemente el resto de sus hijos y su marido esperasen a que ella llegase para hacer la comida para lavar la ropa, para atender a la familia, que en parte se habría pasado el día trabajando bajo el sol y en parte se habría quedado en casa ocupándose de sus hermanos esperando a que su mamá volviese.

Abrimos y comienzan los llantos, uno tras otro, no importa lo tranquilo que estuviese todo, solo es necesario que uno de ellos empiece a llorar y todos parecen aprender el gesto mas rápido que el de al lado. Sentados sobre las piernas de sus mamás intentando digerir la pasta densa que les ofrecemos, ante sus miradas dudosas que intentan comprender y entender que eso será bueno para su hijo.

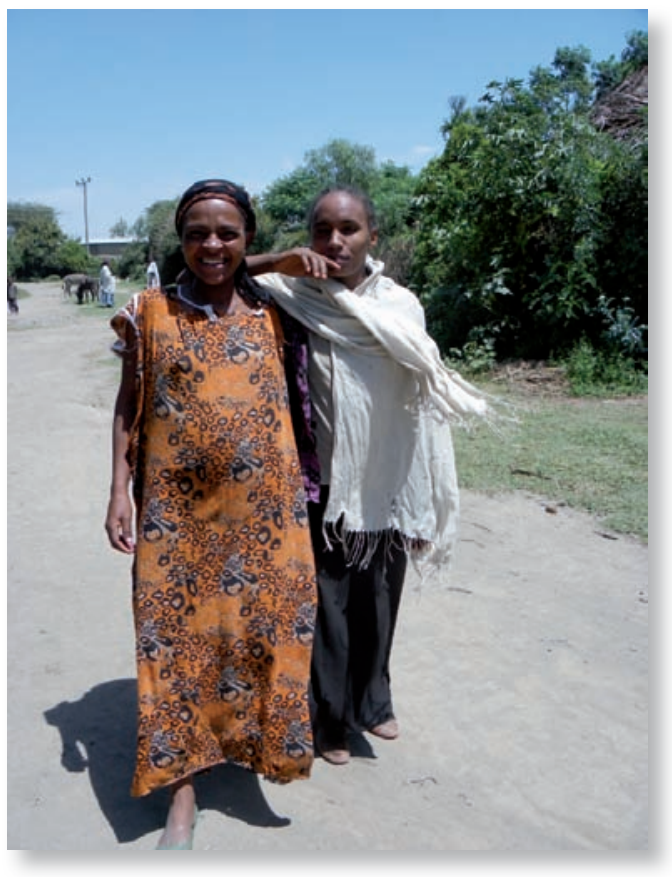

Imagen 2 Madres de Meki

Los niños mal nutridos llegan cansados, débiles, sin fuerza, y reservan su energía para llorar desconsoladamente; lloran y no saben por qué lloran, pero apenas tienen lágrimas. Tienen el pelo y la piel envejecida, color cuero viejo, sin brillo, arrugada, frágiles y delgados, hinchados por el líquido que el organismo no sabe manejar, con los ojos saltones, suplicando atención.

Acojo a la primera madre y su hijo y le explico que vamos a hacer una prueba simple, pero muy importante, algo que nos permite saber si vamos a poder controlar al niño o si por el contrario lo tenemos que trasladar a un hospital especializado. Se lava las manos mientras yo sostengo a su niño, que la persigue con la mirada, que no deja observarla y que llora 
ante la situación de no encontrarse seguro cerca de ella. Pasamos a la sala, donde, sentadas ya con sus niños otras tres madres le dan la bienvenida. Se sienta y pone a su hijo en su regazo. Le explico que el niño debe estar sentado, que el niño debe sentir cariño, y que cuando coma no se le debe forzar, taparle la nariz o echarle la cabeza para atrás, hasta que el guerrero, decida tragar el preparado. Le digo que no debe enfadarse que su hijo está muy enfermo, le digo que no debe gritarle, que no lo zarandee, que no le obligue, que sea paciente. Son cosas que resultan obvias pero cuando uno pierde la paciencia desaparece también la obviedad.

Le facilité un preparado con aspecto de una densa pasta con sabor a cacahuete salado $y$ dulce. A veces llegan con tan poca fuerza que son incapaces de pasar por su garganta la pasta, que se adhiere a las paredes provocándoles finalmente el vómito, en esos casos se diluye con un poco de agua. Es un preparado que los centros reciben gratis, y que tristemente a veces cae en un mercado negro donde la gente lo vende, generalmente a jóvenes que quieren ponerse fuertes y han decidido tomarlo para ganar peso, no tendría mayor importancia, si no fuese porque sabes que cada uno de esos paquetitos de pasta de cacahuete densa es para un niño que realmente lo necesita, niños que están en el borde entre la vida y ... la otra vida ¿quizás?

Poco a poco a los niños se les fuerza lentamente a que ingieran cierta cantidad, dependiendo del peso y poco a poco. Algunos ya acostumbrados, puede ser que no sea la primera vez que tienen que seguir este tratamiento, lo devoran bien a gusto, otros, que ya han perdido incluso las ganas de comer, luchan contra su madre en cada trago para que sea el último. No pueden comer muy rápido, no pueden estar agitados, porque entonces de seguro acabaran vomitándolo todo.
En el transcurso del día observo que dos de los niños apenas han comido nada, luchan y se niegan, lloran y vomitan, los otros dos pasan la prueba tranquilamente. A las madres de los que han comido les damos varios paquetes de pasta de cacahuete hasta el próximo control y se les dice que tienen que traer los sobres vacíos, para evitar que al salir los venda por unas monedas en ese mercado negro de pasta de cacahuete. A los dos que no han comido se les explica que es necesario ir al hospital y se les da dinero para ir al centro. Se incide en que es muy importante que vayan al hospital ese mismo día, para comenzar lo antes posible con el tratamiento, porque su hijo esta muy enfermo.

Comenzamos a preparalo todo y mientras realizamos los trámites, una de las madres se acerca y nos dice que no va a ir al hospital, que no puede, que se va a su casa. Insistimos mucho, pero parece inútil, le explicamos y le decimos con palabras, cada vez más duras, que su hijo se muere. Llama a su marido para buscar aprobación y no la encuentra pero tras nuestra insistencia cede, parece darse cuenta de que es la última oportunidad para su hijo, acepta y les damos el dinero a las dos mamas y se van.

Al cabo de una hora, una de las mamás vuelve desconsolada. Nos relata que la indecisa ha decido finalmente no ir pues centrarse en un hijo puede suponer descuidar al resto. Dejar de lado los trabajos de la huerta para ir al hospital durante dos semanas podría estropear la cosecha que dará de comer al resto de tu familia durante todo el próximo año. Así pues, desanda el camino para decirnos que no se atreve a ir sola, que no sabe cómo tiene que llegar hasta el otro hospital y tiene miedo. Vuelve buscando respuesta a tantas incertidumbres... Le doy escrita la dirección y le explico cómo tiene que llegar, qué autobuses tiene que coger, 
todo muy despacio, con ternura pero emponderándola. Veo salir a la madre y antes de atravesar la puerta metálica, mira una última vez hacia atrás. Ahora depende de ella llegar y conseguir lo mejor para su hijo. La responsabilidad y el cansancio la abruman pero decide seguir adelante.

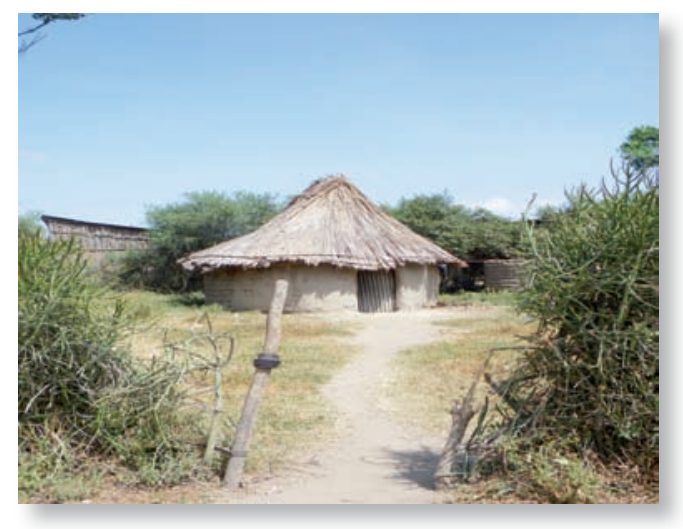

Imagen 3 Casa típica en Meki

\section{AGRADECIMIENTOS.}

A Ana Sendagorta, por su decisión y su alegría por su fuerza que nos inunda. A Jorge y Mar por su compresión y por acogernos en su casa. A los niños del orfanato por la ilusión de una oportunidad. A Carmen Chamizo por su paciencia y su compañía, por ayudarnos a encontrar nuestro camino. 